\title{
Chovendo na roseira de Tom Jobim: uma abordagem schenkeriana
}

\author{
Carlos de Lemos Almada (UNIRIO, Rio de Janeiro, RJ) \\ calmada@globo.com
}

\begin{abstract}
Resumo: 0 presente artigo examina a canção Chovendo na roseira, de Antônio Carlos Jobim, focando as relações estruturais aprofundadas existentes entre melodia, harmonia e forma. Isso é realizado através do método da análise schenkeriana, que recebe aqui algumas adaptações, de maneira a se ajustar apropriadamente às características dessa peça específica. Como resultado do processo analítico observa-se uma integração consistente e hierarquizada entre diversos fenômenos melódico-harmônicos presentes na superfície musical e em camadas estruturais internas, revelando relações inusitadas para uma peça de música popular. É especificamente marcante a onipresença do intervalo de quarta justa, infiltrado nos mais diversos aspectos da construção musical, em todos os níveis estruturais observados.
\end{abstract}

Palavras-chave: Chovendo na roseira; Tom Jobim; análise schenkeriana.

\section{Chovendo na roseira by Tom Jobim: a Schenkerian approach}

Abstract: The present article examines the song Chovendo na roseira by Brazilian composer Antônio Carlos Jobim with focus on the deep structural relationships that exist among melody, harmony, and form. This was accomplished by using procedures of the Schenkerian analysis, here adapted for better adjustment to the characteristics of this specific piece. From the analytical process, it is possible to observe a consistent and hierarchical integration among the several melodic-harmonic phenomena present on the musical surface and some of the internal layers, which reveal relationships that are unusual in a popular music piece. It is especially remarkable the ubiquity of the interval of the perfect fourth, which is embedded in several of the aspects of musical construction, in all structural levels considered.

Keywords: Chovendo na roseira; Tom Jobim; Schenkerian analysis.

\section{Introdução}

A harmonia da bossa nova, em comparação com a de outros gêneros da música popular brasileira (em especial, o samba), é frequentemente qualificada como "sofisticada", o que é em geral atribuído a dois tipos de preferências construtivas: pelo acréscimo de tensões nos acordes (nonas, décimas primeiras e décimas terceiras, por vezes também alteradas) e pela escolha de relações remotas entre estes e o centro tonal de referência (em especial, os acordes pertencentes à classe dos chamados empréstimos modais). ${ }^{1}$

Inúmeras canções de Antônio Carlos Jobim, reconhecidamente o principal compositor do gênero, formam um perfeito exemplo desse tipo de tratamento harmônico, algo que não traz por si só qualquer novidade. 0 que mais impressiona em algumas dessas peças, entretanto, é a existência de relações melódico-harmônicas "subterrâneas", ancoradas em camadas estruturais mais profundas, o que recebe ainda pouca atenção no âmbito acadêmico. ${ }^{2}$

0 presente artigo pretende examinar uma das mais peculiares estruturas melódico-harmônicas dentro da música popular brasileira: aquela que dá corpo à canção jobiniana Chovendo na roseira. Para tal, a análise schenkeriana apresentou-se como o mais adequado método de abordagem, o qual, no entanto, exigiu certas adaptações, tendo em vista algumas características da referida canção (tais adaptações serão explicitadas no decorrer do estudo). 
Cristóbal Gallardo, em um artigo online no qual examina o emprego da análise schenkeriana em peças do repertório de música popular (GALLARDO, 2000), comenta sobre a necessidade de que o próprio objeto de estudo forneça condições propícias que justifiquem tal opção metodológica. ${ }^{3}$ Segundo o autor, essas condições devem corresponder, em diferentes medidas, às assunções mais fundamentais da teoria elaborada por Schenker, das quais a mais importante e determinante para a justificação do emprego do método é que a peça a ser analisada apresente uma linha melódica composta por notas que se subordinem a outras, e que isso possa se observar em relações recursivas, em diferentes niveis estruturais. ${ }^{4}$

É precisamente tal aspecto que justifica a presente abordagem. Como será aqui demonstrado, a canção Chovendo na roseira apresenta um notável planejamento arquitetônico em várias camadas de significação musical, mutuamente conectadas em nítidas relações de hierarquia, a partir de sua própria superfície.

Chovendo na roseira possui algumas características inusitadas dentro do universo bossanovista, como é o caso da métrica ternária ${ }^{5}$ e de sua grande extensão (62 compassos). É possivel subdividí-la em três seções: A (c.1-22); B (c.23-36); C (c.37-51), após a qual segue-se um da capo (c.1-13) e uma coda (c.52-62). É também interessante a organização harmônica da canção, que sugere (ao menos no plano superficial) dois pólos modais (nas seções A e C) intercalados por um trecho firmemente tonal (seção B). ${ }^{6}$

0 Ex.1 apresenta a seção $A$ da canção e três sucessivas reduções analíticas.

Sobre a análise do trecho é possivel fazer as seguintes observações, de acordo com as diferentes camadas consideradas:

- Uma evidente centricidade em Lá e a presença constante (na harmonia e na melodia) da altura Sol, a despeito do Sol\# expresso na armadura de clave da partitura, sugerem uma organização harmônica modal (Lá mixolídio) para o trecho. Uma interpretação alternativa seria considerar toda a seção A como uma prolongação do acorde dominante de Ré maior. Em vista dos desdobramentos futuros, opto por deixar temporariamente a questão em aberto.

- Como se percebe no Ex.1-a, tensões (nonas) e outros acréscimos aos acordes (sextas e quartas, estas em substituição a terças), idiomáticos na bossa nova (assim como na valsa-jazz), apresentam-se aqui como elementos harmônicos estáveis (i.e., sem necessidade de resolução), incorporadas às tríades diatônicas tradicionais.?

- A primeira redução (Ex.1-b) evidencia a importância do Lá inicial como nota principal (Kopfnote, na terminologia schenkeriana). No entanto, ao contrário do que se observa em uma análise schenkeriana tradicional, tal nota não inicia uma linha diatônica des- cendente (Urlinie), seja ela $\hat{8}-\hat{7}-\hat{6}-\hat{5}-\hat{4}-\hat{3}-\hat{2}-\hat{1}$ (no caso da opção pela centricidade em Lá) ou $\hat{5}-\hat{4}-\hat{3}-\hat{2}-\hat{1}$ (na alternativa Ré maior). Observa-se, ao contrário, uma prolongação da nota estrutural Lá por quase toda a seção, seguindo-se de um movimento ascendente em direção a Dó\#, através da nota de passagem Si. Deve-se atentar para o fato de que o Dó\# encontra-se associado não ao acorde inicial (I grau em Lá mixolídio ou V em Ré maior), o que implicaria uma simples prolongação harmônica da fundamental à terça, mas a um acorde de qualidade de sétima dominante sobre a fundamental Fá\#, como sua quinta. ${ }^{8}$ Como se observa no Ex.1-b, a tal progressão melódica de terça ascendente Lá-Dó\# corresponde um movimento espelhado na linha do baixo, descrevendo também um intervalo de terça, porém descendente (Lá-Fá\#), em cujo âmbito a nota SolŁ, embora não presente na partitura, é nitidamente implícita. 0 Ex.2 resume sucintamente toda a seção $A$, revelando o interessante esquema de simetria espelhada, cujo eixo é a própria Kopfnote Lá.

- É consideravelmente significativa para a estruturação global da canção a presença do intervalo de quarta justa descendente - justamente o motivo melódico que inicia a peça - entre as notas Lá e Mi (c.12) e Mi e Si (c.5-6, repetido nos c.9-10). Tal aspecto da melodia (saliente na própria superfície musical) é suportado pelo plano harmônico, o que se constata através da proeminência de acordes de qualidade dominante com quarta suspensa:9 A7(sus4) (alternando com A6 entre os c.1-18) e F\#7 (sus4) (em alternância com F\#7 entre os c.19-22). No exame das demais seções a ubiquidade do intervalo de quarta será ainda mais enfatizada, tanto nos aspectos melódico quanto rítmico.

A análise da seção B (c.23-36) é apresentada no Ex.3, compondo-se do nível superficial e de duas reduções.

Observações:

- É fácil perceber no Ex.3-a uma segmentação simétrica dos 14 compassos da seção $B$ em duas metades (c.23-29 e c.30-36), em um nítido esquema de sequenciação estrita de modelo por intervalo de segunda maior descendente.

- Chama também a atenção no superfície musical a onipresença da relação intervalar de quarta justa ascendente entre as fundamentais dos acordes em cada metade da seção.

- Como se observa no Ex.3-b, o motivo melódico principal da canção, o salto de quarta justa descendente (ver Ex.1-b), é aqui ampliado para quinta (inversão intervalar da quarta), propagando-se em sequência. Fica evidente na redução a existência de uma melodia composta, formada por duas linhas escalares descendentes que, como se constata no Ex.3-c, têm como objetivo prolongar os acordes principais em cada uma das duas metades da seção, respectivamente, D7M9 e C7M9. 

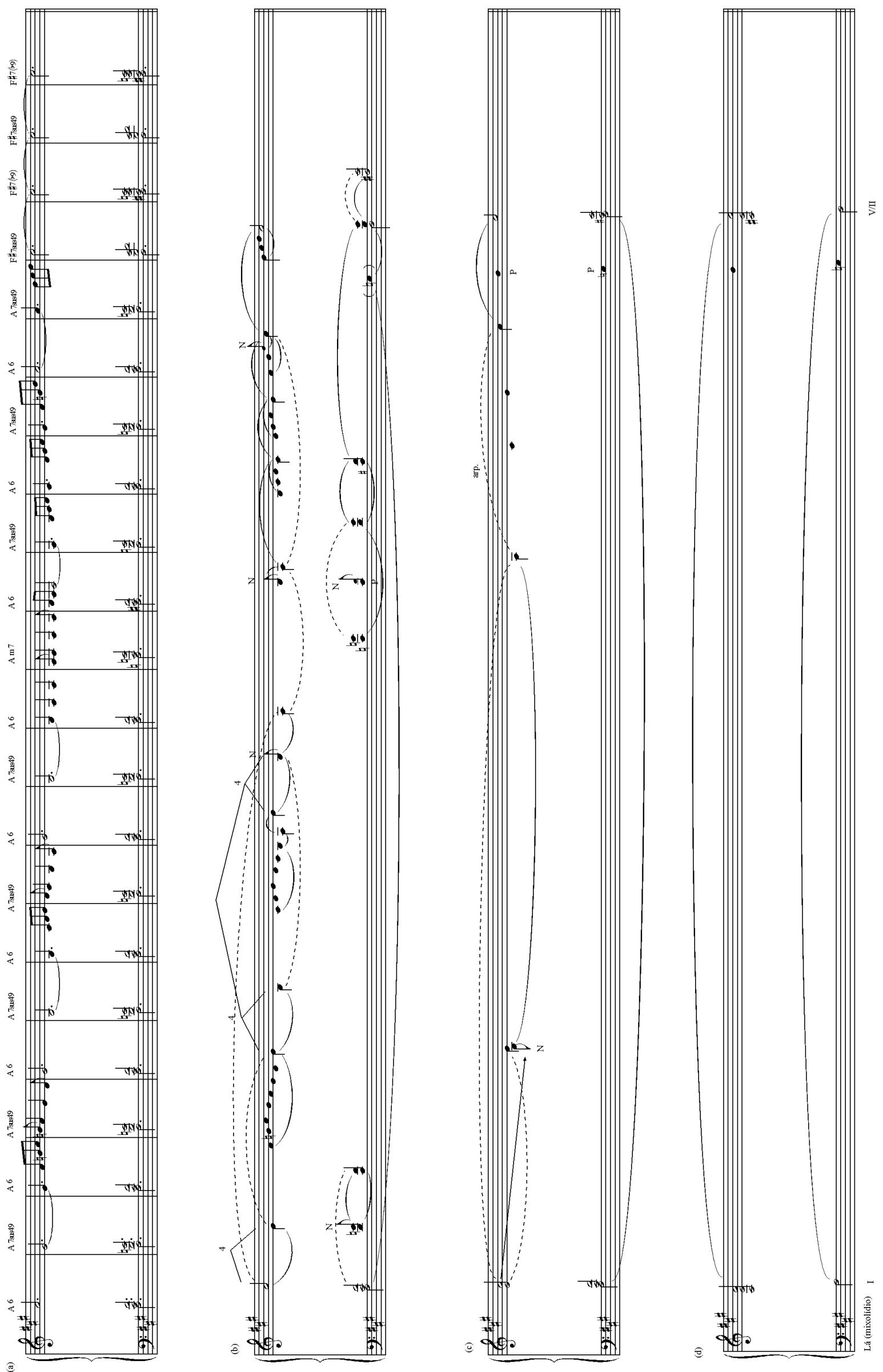

Ex.1 - Chovendo na roseira, seção A (c.1-22): a) superfície; b) c) d) três níveis intermediários. 
- Sob uma perspectiva estrutural mais ampla, podemos considerar a primeira metade (centrada em Ré) como hierarquicamente superior à segunda (em Dó). Isto se deve basicamente a dois fatos: (1) a Kopfnote Ré consititui-se um objetivo esperado, a partir dos acontecimentos desenrolados na seção $A$, tanto no plano harmônico - a prolongação de $A 7$ - quanto no melódico - a ascenção Lá-Si-Dó\# (ver Ex.2); (2) Dó, na metade da seção $B$, funciona, assim, como uma passagem não-diatônica entre as notas estruturais Ré e Si, esta como cabeça da seção C (ver Ex.4).

Observações referentes à seção C (Ex.4):

- A forte semelhança desta linha melódica com aquela da seção A (comparar especialmente a atuação do motivo principal, Exs. 1-b e 4-b), bem como a manutenção de um pedal sobre o centro de referência (neste caso, Si) sugerem para o trecho a função de reexposição da parte principal, ainda que variada e transposta por intervalo de segunda maior ascendente. Contudo, tal paralelismo é atenuado por um fator ao mesmo tempo distintivo e decisivo: uma linha cromática descendente, de $\mathrm{Mi}_{3}$ a $\mathrm{Mi}_{2}$ (em destaque no Ex.4-b), extraída como voz interna no encadeamento dos acordes. ${ }^{10}$ De acordo com a presente análise, é justamente tal linha, associada ao pedal em Si, que orienta a estrutura harmônica da seção e, consequentemente, a própria escolha dos acordes.

- A linha cromática transforma-se, assim, de um elemento subordinado e relativamente oculto na superfície musical em fator determinantemente estrutural em níveis mais profundos, desmontando o paralelismo mais evidente entre os fenômenos musicais das duas seções. A prolongação do Mi (através da escala cromática) rivaliza-se em importância àquela do Si da linha melódica principal, o que leva à conclusão de que, ao contrário do que acontece na seção $A$, a harmonia prolongada não é a que inicia o trecho (B7), mas sim a que o finaliza (E7), como evidencia o Ex.4-c.

- $\quad 0$ Ex.5 resume e agrupa as análises das três seções (Exs.1, 3 e 4), com o acréscimo da recapitulação da seção $A$ e o subsequente pulo para a coda (que nada mais é do que uma prolongação das sonoridades iniciais), apresentando uma estrutura análoga à habitual Ursatz da análise schenkeriana.

Desse esquema podem ser extraídas algumas observações interessantes:
- A centralidade em Lá é incontestável, o que inviabiliza a alternativa de Ré maior como tonalidade principal da canção.

- No lugar de uma Urlinie convencional, percebe-se uma estrutura melódica básica descrevendo um arco de quarta justa ascendente (em percurso diatônico), e que retorna ao ponto de partida de maneira quase cromática, com um apoio intermediário no segundo grau da escala (na seção C);

- 0 intervalo de quarta justa é também evidenciado como relação proeminente entre os baixos estruturais. 0 esquema permite considerar o até aqui "enigmático" Fá\# da seção A como a dominante secundária do Si que encabeça a seção $C$ (ver a ligadura prolongacional entre as duas notas no Ex.5), com a seção B (centrada em Ré) intermediando a resolução. Um reordenamento dos baixos principais explicita ainda mais a importância do movimento de quartas como elemento estrutural na canção (Ex.6);

\section{Conclusões}

Este estudo buscou examinar as complexas relações estruturais presentes na canção Chovendo na roseira. Para isso tornou-se necessário o emprego dos recursos da análise schenkeriana que, a despeito das adaptações efetuadas, em virtude das características específicas da peça, mostrou-se como a ferramenta ideal para tal investigação no grau de profundidade adequado. É especialmente marcante na análise da canção a presença do intervalo de quarta justa, nos mais variados aspectos e niveis estruturais, desde o principal motivo melódico (na superfície musical) à arquitetura harmônica básica (apresentada pelas relações de baixos primordiais), passando pela organização formal das seções, pela constituição de vários acordes (aqueles com quarta substituta e com nonas acrescentadas) e pelo próprio contorno da - por analogia - "Urlinie" resultante. É também interessante constatar que o modalismo (mixolídio) presente nas seções A e C é um fenômeno meramente superficial, sendo, por assim dizer, neutralizado sob uma perspectiva mais básica, o que se observa nas relações harmônicas da "Ursatz" da canção (ver Ex.5). Julgo que os resultados obtidos estimulam a aplicação de novas adaptações do método schenkeriano em outras análises futuras de peças de Antônio Carlos Jobim, principalmente visando investigar se a extraordinária capacidade de organização musical em camadas estruturais constatada neste trabalho está também presente em outras obras do rico e variado repertório desse formidável compositor.

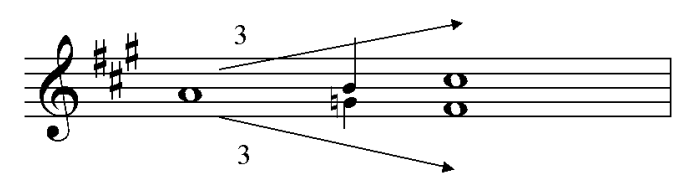

Ex.2 - Chovendo na roseira, seção A (c.1-22): plano geral 

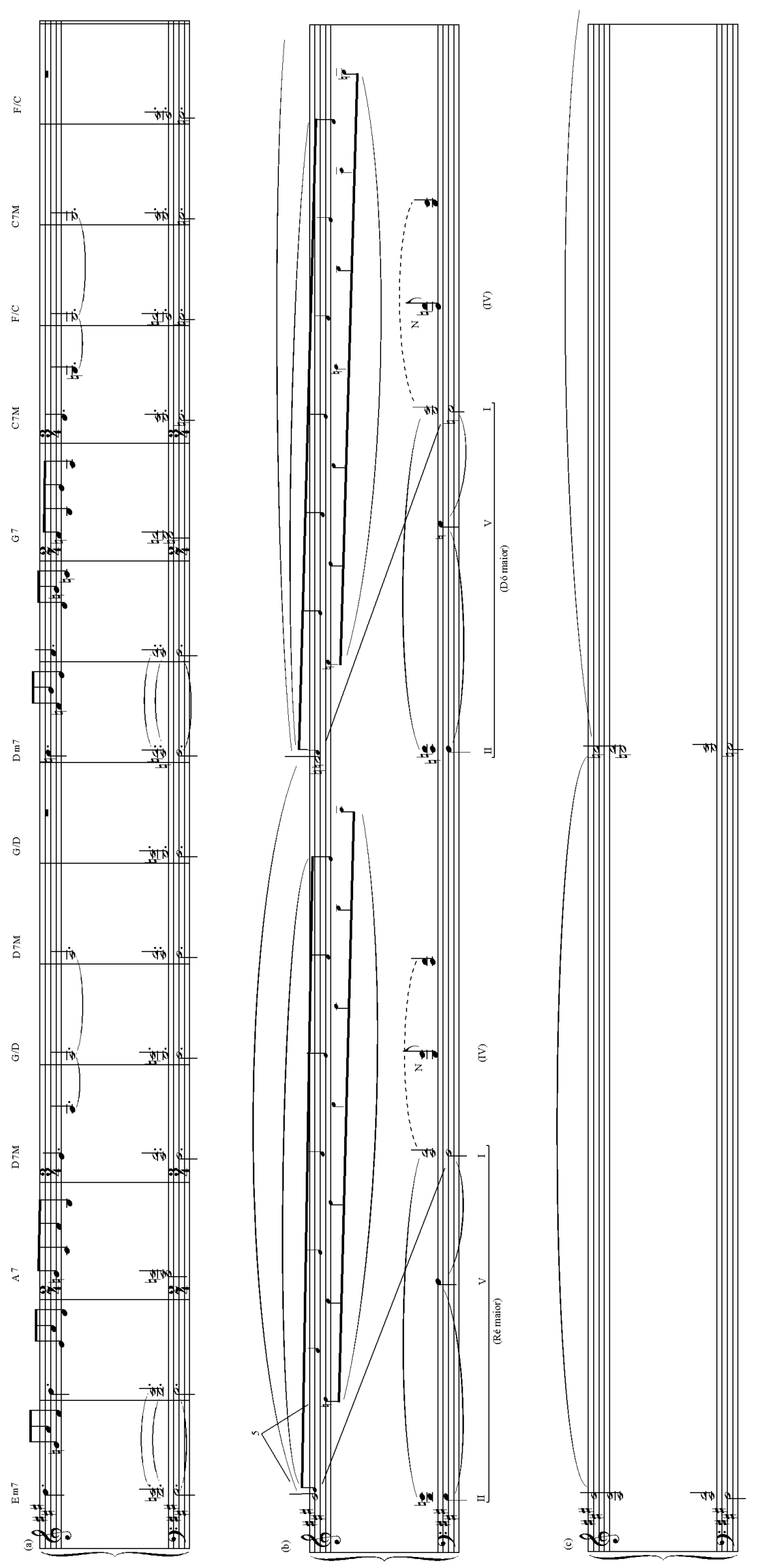

Ex.3 - Chovendo na roseira, seção B (c.23-36): a) superficie; b) c) dois niveis intermediários. 


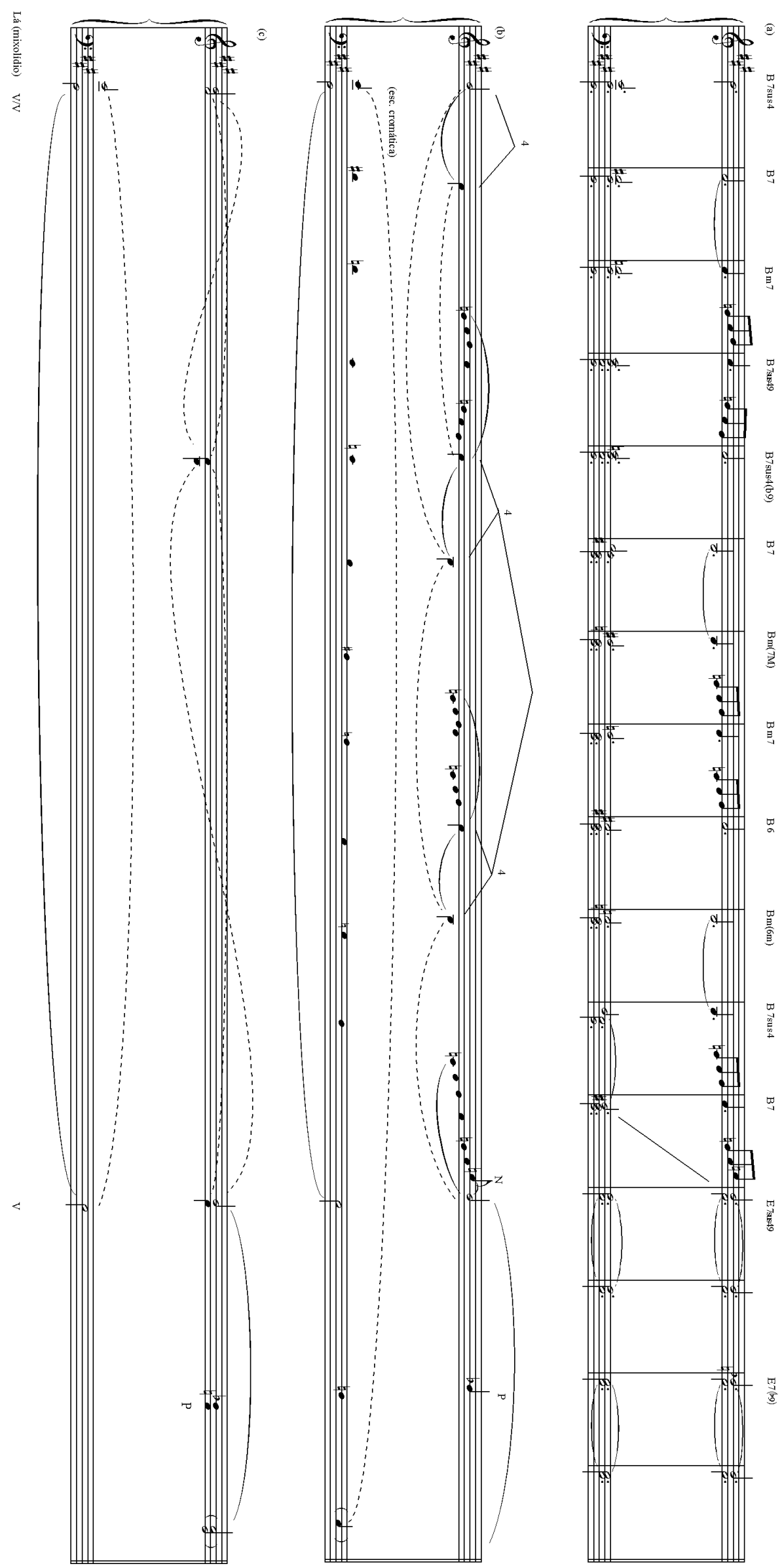

Ex.4 - Chovendo na roseira, seção C (c.37-51): a) superfície; b) c) dois niveis intermediários 


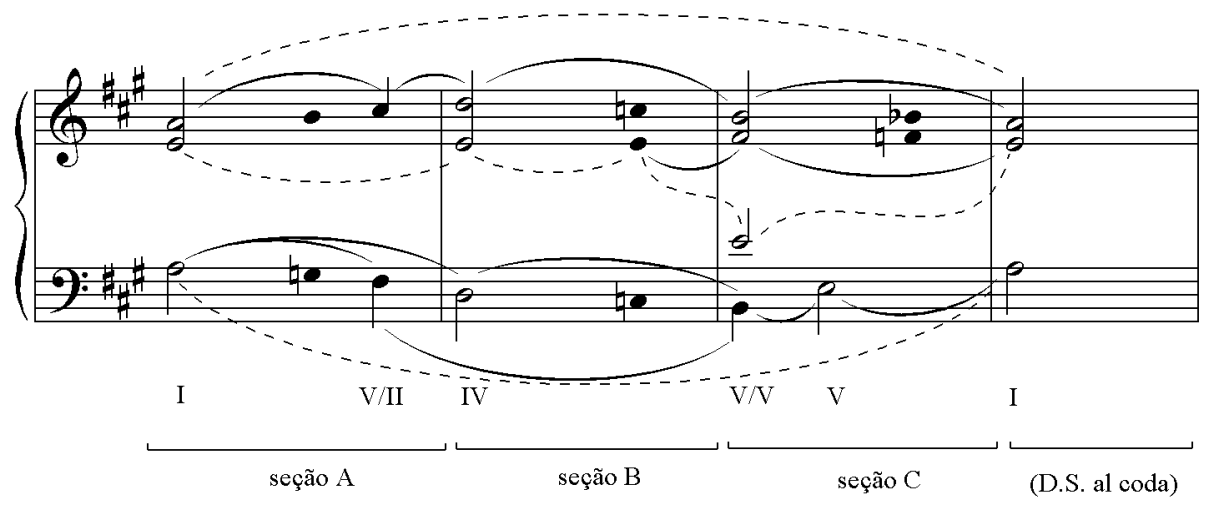

Ex.5 - Chovendo na roseira, estrutura primordial

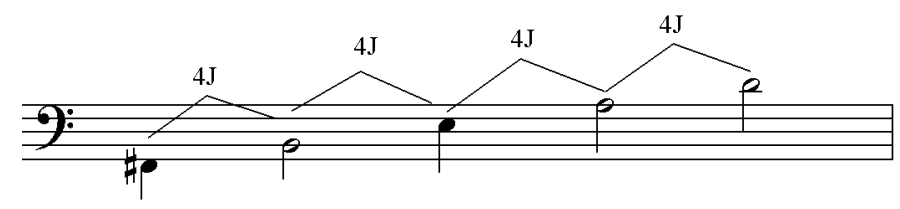

Ex.6 - Chovendo na roseira, reordenamento da sequência dos baixos estruturais

\section{Referências}

ALMADA, Carlos de L. Samba de uma nota só: elementos musicais a serviço da expressão poética. In: XIX ENCONTRO ANUAL DA ANPPOM, 2009. Curitiba. Anais ... Curitiba: UFPR, 2009. 1 CD-ROM (3 p.).

FORTE, Allen. The American popular ballad of golden era., 1924-50. Princeton: Princeton University Press, 1995.

GALLARDO, Cristóbal L. Garcia. Schenkerian analysis and popular music. Transcultural Music Review, n 5, 2000. Disponivel em: http://www.sibetrans.com/trans/trans5/garcia.htm. Acesso em: 30/10/2009.

GAVA, José E. A linguagem harmônica da bossa nova. São Paulo: Editora UNESP, 2002.

GILBERT, Steven E. Gershwin's art of counterpoint. Musical Quaterly, № 70/4, p. 423-56, 1984.

INSTITUTO ANTÔNIO CARLOS JOBIM. Disponivel em: http://www.jobim.org/jspui/acervo/acervodigital.jsp. Acesso em: $15 / 5 / 2009$.

JOBIM, Antônio C. Chovendo na roseira. In: Songbook Tom Jobim (vol. 3). Partitura. Rio de Janeiro: Lumiar, 1994, p. 32-34. MIDDLETON, Richard. Studying popular music. Buckingham: Open University Press, 2002.

PY, Bruno de Oliveira. Estrutura tonal na obra de Tom Jobim: uma abordagem schenkeriana da canção "Sabiá". 2004.

Dissertação (Mestrado em Música) - Escola de Música, Universidade Federal do Rio de Janeiro. 


\section{Notas}

1 Para análises harmônicas de peças bossanovistas ver, por exemplo, GAVA (2002).

2 Para uma análise estrutural de uma canção de Jobim (em parceria com Newton Mendonça) - Samba de Uma Nota Só -, com enfoque especial na relação entre texto e música, ver ALMADA (2009). Ver também PY (2004), que realiza uma abordagem de Sabiá, outra famosa composição de Jobim, a partir dos métodos da análise schenkeriana.

3 É também pertinente conhecer o pensamento de Richard Middleton sobre o assunto: "não há razões para que a análise schenkeriana não possa ser aplicada em canções populares regidas pelo processo funcional tonal" (MIDDLETON, apud PY, 2004, p.21).

4 Outros pré-requisitos seriam: idioma tonal, estrutura harmônica calcada em triades diatônicas (em especial, os graus I e V) e que a melodia da peça possa ser reduzida a uma linha descendente diatônica e em graus conjuntos (Urlinie), iniciando-se em III ( $\hat{3}), \mathrm{V}(\hat{5})$ ou I ( $\hat{8})$. Contudo, o próprio autor admite que tais "exigências" podem ser atenuadas ou até mesmo suprimidas de acordo com as particularidades de cada situação. É o caso, por exemplo, do característico emprego de tensões harmônicas não resolvidas em certos gêneros da música popular - entre os quais, a bossa nova -, o que concede a tétrades e pêntades estabilidade análoga à das triades tradicionais. De acordo com Schenker, as dissonâncias presentes na superfície de uma peça musical nascem dos movimentos contrapontísticos das vozes, a partir de consonâncias, hierarquicamente superiores. Segundo Gallardo, a discordância em relação a esse preceito schenkeriano não necessariamente desqualificaria uma análise. Como será mencionado, a utilização de tensões não resolvidas em acordes estruturalmente estáveis também acontece em Chovendo na Roseira

5 Em nome de uma maior precisão, talvez fosse mais apropriado classificar Chovendo na Roseira como representante do gênero "valsa-jazz" (e não como uma típica canção bossanovista), considerando não apenas os contornos rítmicos de sua linha melódica, calcados essencialmente em grupos de colcheias, mas principalmente a execução destas, efetuada dentro do assim chamado jazz feeling (i.e., dividindo os tempos na proporção 2/3-1/3, no lugar da notada 1/2-1/2). Contudo, seja qual for a opção escolhida para a classificação do gênero da canção, trata-se de um fator de pouca ou nenhuma relevância para os objetivos deste trabalho.

6 Como será demonstrado, o caráter modal das seções $A$ e $C$ representam fenômenos relativamente superficiais: estratos mais profundos revelam novos papéis para essas seções no esquema global da estrutura harmônica.

7 Este aspecto é enfatizado por Gallardo como uma das adaptações necessárias em análise schenkerianas de peças de música popular. 0 autor cita especialmente trabalhos de Steven Gilbert (1984), a partir de análises de obras de George Gershwin, e de Allen Forte (1995), sobre a balada popular norteamericana, em cujo texto foi cunhada a expressão "dissonâncias estáveis" [stable dissonances] (FORTE, 1997, p. 43).

8 A presença desse acorde tem um caráter um tanto enigmático, já que não é resolvido da maneira convencional. A razão de sua existência, como será visto, só se revela sob uma perspectiva mais global da estrutura da peça.

9 Ou seja, acordes de sétima dominante nos quais a terça maior é substituída pela quarta justa. Por exemplo, as notas que compõem A7(sus4) são: Lá, Ré (substituindo Dó\#), Mi e Sol. As mesmas notas dispostas como Mi-Lá-Ré-Sol constituem uma sucessão de três quartas justas ascendentes (a inclusão da nona do acorde - Si - no grupo amplia ainda mais a sequência quartal).

100 encadeamento de acordes baseado na escala cromática descendente é uma das caracteristicas mais marcantes da construção harmônica de Jobim. A condução cromática, no entanto, apresenta-se em geral na linha do baixo (por exemplo, em Samba de Uma Nota Só, Corcovado, Inútil Paisagem, Brigas Nunca Mais, etc.). Para maiores detalhes, ver ALMADA (2009, p. 704-6).

Carlos de Lemos Almada é flautista, compositor, arranjador, professor e autor de livros sobre teoria musical e análise ("Arranjo", Editora da Unicamp, 2000, "A estrutura do choro", Editora Da Fonseca, 2006 e "Harmonia funcional", Editora da Unicamp, 2009). É doutorando em Música pela Universidade Federal do Estado do Rio de Janeiro, cuja pesquisa visa a análise da estrutura harmônica da Primeira Sinfonia de Câmara, op.9, de Arnold Schoenberg, dando continuidade a estudo realizado sobre a estrutura formal da mesma obra, durante o mestrado. Atualmente é professor de Harmonia e Análise na Escola de Música da Universidade Federal do Rio de Janeiro (UFRJ). 